IRSH 62 (2017), pp. 495-500 doi:10.1017/S0020859017000402

(C) 2017 Internationaal Instituut voor Sociale Geschiedenis

\title{
Obliterating Boundaries, Questioning Borders: A Comment on Globalising Migration History
}

\author{
Leslie Page Moch \\ Department of History, Michigan State University \\ East Lansing, MI 48824, USA \\ E-mail: leslie@msu.edu
}

Jan and Leo Lucassen have undertaken an ambitious task - to make migration universally legible to scholars and to public discourse by rendering migration worldwide comparable and measurable, like the gross national product or rates of literacy. In order to approach this task, they have, of necessity, created new datasets - for this alone they are to be congratulated, for undertaking tasks that require a combination of hubris and the willingness to make important decisions about the categorization of human movement along with incorporating room for error. To bring twentieth-century Russia into the picture, especially after 1950, is a signal contribution. The databases used to calculate the cross-cultural migration rates (CCMRs) are a project and an achievement, only conceivable within the companion task of creating an analytic scheme that will work universally.

If datasets are hard won, conceptual schemes are always debatable. The fundamental distinctions and decisions about human migration here were designed to create a scheme that would work in all the arenas from which most major migration studies originated: transatlantic, Western European, decolonizing, and transpacific - as well as the content of this volume, the great landmass of Eurasia. Some of this book focuses on what Adam McKeown calls the North Asian System - one of the three great migration systems in which millions of people moved in the nineteenth and twentieth centuries: across the Atlantic, across the Pacific, and, in this case, it includes movement into Siberia, Manchuria, and Mongolia, regions in which the Russian and Chinese states settled colonists in competition for these vast areas. $^{\mathrm{I}}$

The Lucassens's conceptualization of migration includes ways of moving that are not always considered migration. First, and most importantly, they do not exclude internal migration, recognizing that movements that do not transcend international borders can involve as much displacement as 
international moves. The historical migrations of rural patois-speaking young women to cities to work as domestics in middle-class households, for example, demand shifts in language use and culture. The same can certainly be said of what Americans call "the great migration" from the south to the northern US in the twentieth century. Moreover, in a political unit as large as the USSR or Imperial Russia, the move from Vladivostok to Leningrad/St Petersburg or from Irkutsk to Moscow involved a longer trip than crossing the Atlantic as well as a remarkable change of scene, scale, and culture. ${ }^{2}$

Nor do the Lucassens exclude temporary migration - seasonal and temporary workers and sojourners who returned home after months or a period of years and thus defied the idea that only those who leave home definitively can be considered true migrants. This crucial inclusion corrects a fundamental misunderstanding of migration that lay at the heart of its data sources and interpretations. The urbanward and international migrations that are effectively recorded in many censuses tell us nothing about the high turnover of populations in a world in which movement was the norm. The great volume of temporary migration is captured only by specific sources, such as Prussian migration statistics gathered at the local level (Meldewesen), and these have revealed a world of movement largely ignored until recent years, confirming migration as normal behavior in a wide range of societies, rather than a symptom of pathology. ${ }^{3}$

Finally, and crucially, the Lucassens include coerced migration. This is salutary on two counts, the first being that coerced migration is of great historical importance for the numbers of people moved against their will, the depredations to their home places, and the crucial roles they played at destination. Moreover, there is a spectrum of coercion - from capture and chattel slavery to exile; from expulsion, forced refugeedom, and coerced evacuation in wartime to wage slavery - and, as a consequence, to exclude coercion is to ignore not only chattel slavery and expulsion, but also the role that coercion plays in many migrations.

On the other hand, to measure crossing cultural boundaries as migration is fraught with difficulty because it implies that to move into a place with distinct values and norms is "more transformative", which links migration to self-development in a somewhat Whiggish way. We see how this is

2. See, for example, Leslie Page Moch, The Pariahs of Yesterday: Breton Migrants in Paris (Durham, NC, 2012); Lewis H. Siegelbaum and Leslie Page Moch, Broad Is My Native Land: Repertoires and Regimes of Migration in Russia's Twentieth Century (Ithaca, NY, 20I4). For an extraordinary entry into the literature on the Great Migration, see Isabel Wilkerson, The Warmth of Other Suns: The Epic Story of America's Great Migration (New York, 2010); and James Gregory, The Southern Diaspora: How The Great Migrations of Black and White Southerners Transformed America (Chapel Hill, NC, 2005).

3. See Steve Hochstadt, Mobility and Modernity: Migration in Germany, I820-1989 (Ann Arbor, MI, 1999). 
inappropriate today because some proletarian migrations hardly enhance workers' lives in a positive direction. Moreover, much colonizing migration was undertaken in order to maintain a standard of living while continuing to farm, and temporary migration to the city was often undertaken in order to maintain rural lives. Nonetheless, the idea of crossing cultural borders has value despite the risks of ambiguity - historians are at home in untidy territories.

The capacious definitions of migrations in Globalising Migration History free us to peruse forms of cross-cultural migrations that receive short shrift in this volume. With the implementation of universal compulsory education, for example, normal school graduates were sent to far-flung villages where, in the case of France (and elsewhere), they met with students who did not speak the national language and families who were hostile to schooling. In Russia's twentieth century, several such temporary multi-year migrants come to mind, in addition to the undercounted seasonal and temporary movers. Armies of bureaucrats and other manner of state employees, such as farm managers, were sent out every year in the Soviet Union, but do not make their way into the CCMR "temporary multiannual" category of migrants. Refugees within Russia, who numbered in the hundreds of thousands during World War I, have no place in this scheme, nor do the millions of evacuees from the Western front during World War II - thousands of whom discovered a quite different culture in Uzbekistan and Kazakhstan. Wartime evacuees undergird the key role of wars in mobility in the twentieth century, honored by the Lucassens. ${ }^{4}$ Here, we are in the arena of internal migrants who have little choice, and with them are the "dekulakized" peasants sent to special settlements in the I930s, distinct from the Gulag, who numbered in the hundreds of thousands and who developed forestry and mining in hostile climates. ${ }^{5}$

With those of little choice come soldiers, drafted into service by the millions in twentieth-century Russia and elsewhere, usually as young men (but including rafts of women and the middle-aged). The caution demonstrated by the Lucassens in double counting soldiers is admirable, but I must also observe that it is difficult to overcount migrants, given that one lifetime allowed movement as a newcomer to the city, seasonal work, temporary military service, and plausibly migration for another career. And perhaps internal deportation or imprisonment far from home.

Ideally, the Lucassens agree, domestic servants should be included in global comparisons of migration rates, as difficult as it is to gather "good and systematic data" about their movements. This omission is 
regrettable, because the omission of rural women working temporarily in towns and cities as domestics "underestimates high levels of mobility in early modern cities". ${ }^{6}$ Not only that, the employment of domestics has a broader temporal and geographic scope than early modern Europe, to which current scholarship is devoted. ${ }^{7}$ Domestic workers constituted an important migratory force worldwide in the twentieth century that begs for systematic scholarly attention. Moreover, because the lion's share of (but by no means all) domestic workers were and are women, their exclusion perpetuates (and renders even more official) the vision of the migrant as a male, even when that was not so. Gathering data on domestics who move within their home country or abroad is a challenge, particularly because states are so much more interested in counting their soldiers than their servants, who were of no use, except as producers of remittances. ${ }^{8}$ Fortunately, historian Donna Gabaccia and sociologist Katharine Donato together have carefully investigated the data for and meanings of sex ratios in historical transnational migration; their study will serve scholars well. ${ }^{9}$

In short, the datasets for and conceptualization of cross-cultural migration rates are a significant achievement of Globalising Migration History; one may quibble about the details, but this is an advance that will allow scholars to speak cogently across borders and disciplines. And this is not the half of it, because the global migration history project has underwritten and organized meetings of scholars in Taipei and Rabat to share their research scholars who work in the Netherlands, China, India, Japan, Russia, the United Kingdom, and the United States. Consequently, the twelve substantive essays in this collection offer a terrific panorama of Asian migrations that cannot be neglected in the discussion of its editors' conceptual framework.

The essays begin with Willard Sunderland's and Gijs Kessler's essays on the reach of tsarist Russia into Asia (especially Siberia). At the end of his essay, Kessler offers a stimulating reflection comparing the Russian and

6. Jan Lucassen and Leo Lucassen (eds), Globalising Migration History. The Eurasian Experience (I6th-2 Ist Centuries) (Leiden, 2014), p. I8.

7. To cite one inclusive example of the many publications that have appeared this century, Dirk Hoerder, Elise van Nederveen Meerkerk, and Silke Neunsinger (eds), Towards a Global History of Domestic and Caregiving Workers (Leiden, 2015).

8. See, for an excellent founding example, Rhacel Perreñas, Servants of Globalization: Women, Migration, and Domestic Work (Stanford, CA, 200I). For the "feminization of migration", see Marlou Schrover, "Feminization and Problematization of Migration: Europe in the Nineteenth and Twentieth Centuries", in Dirk Hoerder and Amarjit Kaur (eds), Proletarian and Gendered Mass Migrations: A Global Perspective on Continuities and Discontinuities from the 19th to the 2 Ist Centuries (Leiden, 2013), pp. I03-I 3 I.

9. Katharine Donato and Donna Gabaccia, Gender and International Migration: From the Slavery Era to the Global Age (New York, 2015). 
Chinese empires. For historians of the West, the essays on South Asia are revelatory. First, Vijaya Ramaswamy elucidates the mobility of the weavers in South India who created beautiful saris, among other products; this provides part of some new work to map early migrations within India, in this case from the thirteenth to the eighteenth centuries. Then, Sunil Anrith measures the comings and goings of South Asians to Southeast Asia, tracing plantation labor in Malaya, Burma, and Ceylon.

The heart of the revelations for the Europeanist appear in the section on Southeast Asia. Although Ulbe Bosma focuses on migration and colonialism in nineteenth-century Java, he points to both the complexity and multiplicity of patterns of mobility (agricultural and otherwise) as well as to the set-up for the twentieth-century large-scale movement of domestics and construction workers to Malaysia. Atsushi Ota elucidates a plethora of migrations in the Malay Archipelago, I750-1850, demonstrating to the reader that migration patterns of actual human beings are more complex than scholars can manage. Commercial and enslaved migrants, laborers in tin and gold mines, and "maritime migrants" in search of sea and forest products all predate industrialization. To students of Malaysia, Indonesian, Chinese, and other Asian histories, migrants offer no surprise. Mireille Mazard makes a singular contribution in her study of the Lisu, a highland people of Southeast Asia; her point, in a way, is just how singular the Lisu were, and certainly a poor fit with James Scott's freedom-loving highlanders. ${ }^{\circ}{ }^{\circ}$ Jelle van Lottum concludes this section with his study of migration in twentieth-century Indonesia - an age of jolting change, decolonization, and industrialization, each of which is reputed to have dramatically affected migration patterns. Like Kessler in Section One, Van Lottum uses data that lends itself to CCM categories and analysis, tracing the movement from migration to the land to urbanization and asserting that decolonization did not affect the rates of migration.

The final section, on East Asia, begins with Adam McKeown on China, I600-1900, in which the author opens with the forthright question: "Is there a world history of migration?" McKeown goes on to confirm that "the CCMR-model offers an excellent point of departure to embark upon a comparative global history of migration". He denotes the difficulty of comparisons ("China is an empire. Europe is a continent" ${ }^{\prime}$ ) and nonetheless compares the two: both Europe and China underwent what has come to be called a mobility transition, i 850-1900, but the increase in mobility came from distinct causes - in the case of China, from war, "violence, destruction, refugees". McKeown poses stimulating questions

I. James Scott, The Art of Not Being Governed: An Anarchist History of Upland Southeast Asia (New Haven, CT, 2009).

I I. Adam McKeown, "A Different Transition: Human Mobility in China, I600-1900", in Lucassen and Lucassen, Globalising Migration History, pp. 279, 28I. 
about distinctions among these kinds of migration that are also important in Russia's twentieth century. Next, Yuki Umeno takes on the North Asian migration system in his study of Han Chinese in Manchuria, I $850-193 \mathrm{I}$. Like the earlier study of South Indian weavers, Umeno uses village-level studies to elucidate, in this case, the millions of Chinese moving to Manchuria. Jianfa Shen takes a much wider perspective in an essay on China after Mao. Using the terms of CCM, the reader understands the inexact boundaries between states and among migrants, soldiers, and settlers. Migration to the land, so important in the decades after the revolution, gave way almost entirely to urbanization. The final substantive essay reflects the labors of three authors: Leo Lucassen, Osamu Saito, and Ryuto Shimada; this trio surveys cross-cultural migrations in Japan since 1600 and finds, as elsewhere, unprecedented movement in the 1900-1950 period. Here, too, the authors were able to use data in the CCM categories.

This volume required a strong editorial hand to produce the coherence that it has achieved - and many of the authors (Gijs Kessler, Jelle van Lottum, Adam McKeown, Jianfa Shen, Leo Lucassen) were able to utilize data that fit CCM categories of immigration, emigration, movement to cities, temporary/multi-year movement, and colonization. Nonetheless, this is a historians' work, which allowed for very particularistic datasets, contingencies, and migration patterns. Globalising Migration History not only offers definitions and comparable data, then, it also demonstrates openness to the realities of human mobility in all its variety. The editors express the hope that "such an approach will enable us to free migration studies from its own, specialist, confines and integrate it into global history". ${ }^{\mathrm{I} 2}$ They have given it a fighting chance. 